patient had been told by her medical adviser that she had a "weak heart." She died 12 days after her last admission.

At the necropsy the hemiplegic condition was found to be due to cerebral embolism, but all interest centred round the cardiac condition. The pericardium was healthy and its sac contained the usual quantity of clear fluid. There was considerable fatty infiltration over the right ventricle. The cardiac muscle was somewhat pale and soft, and there was a slight streaky appearance of the endocardium. The left ventricle appeared normal as regards size and showed no hypertrophy. The right ventricle was dilated and hypertrophied. The left auricle was greatly dilated and showed considerable hypertrophy; it was distended with blood and its appendix was filled with adherent ante-mortem thrombus, otherwise the auricular walls were perfectly smooth. Lying quite free in this auricle there was found a ball-thrombus $1 \frac{1}{2}$ inches in diameter and practically spherical. Its surface was perfectly smooth. Its colour and appearance were similar to those of the surface of a normal healthy kidney after removing the capsule. One-half of the sphere was rather paler in colour than the other. On palpation it felt as if it contained fluid. On section it was found to consist of a well-defined wall fully one-eighth of an inch in thickness, inclosing flaky clotted blood, which in the centre had undergone liquefaction. The mitral orifice was markedly stenosed, only admitting the tip of the little finger. The mitral cusps were greatly thickened and adherent to each other so as to leave only a circular opening; the chordæ tendineæ were thickened and shortened, and altogether the mitral orifice had the typical "funnelshape." On holding up the opened left auricle it was seen that the ball could rest well into and over the mitral orifice like a ball-valve. The aortic valve was slightly incompetent and the cusps showed thickening along their lines of contact. The first part of the aorta showed slight dilatation. The right auricle showed some dilatation and slight hypertrophy, and there was some ante-mortem thrombus present in the appendix. The tricuspid and pulmonary valves were normal. The aorta showed slight atheroma around the orifices of the intercostal arteries, but there was no loss of elasticity. With the exception of some congestion of the lower lobe of the right side, both lungs showed no morbid change. The liver was normal in size, showed some old perihepatitis, but otherwise appeared healthy. The spleen was enlarged, firm in consistence, and showed a large hæmorrhagic infarction. There was considerable old perisplenitis. The right kidney ( 6 ounces) was double the size of the left ( 3 ounces). Their capsules were markedly adherent and the surfaces showed numerous cicatricial indentations from old infarctions. On section the kidneys showed considerable disintegration from old infarctions. There was a minute calcified tubercle in the upper part of the right kidney. There were numerous large calcareous deposits in the mesentery, but beyond this there was nothing of interest in the abdomen.

In this hospital, where over 400 post-mortem examinations are performed every year, it is worthy of note that there is only one similar specimen of ball-thrombus in the Pathological Museum. It is about the size of a walnut, but its surface is rough and corrugated and its wall not more than one-sixteenth of an inch thick. It was obtained from the right ventricle of a man, aged 64 jears.

Glasgow.

\section{TWO REMARKABLE CASES OF SUDDEN DEATH FROM UNSUSPECTED CARDIAC LESION.}

BY HUGH GALT, M.B., B.Sc. GLASG., F.F.P.S. GLASG., PATHOLOGISY TO THE ROYAL INFIRMARY, GLASGOW.

APART from the intrinsic interest of the following two cases/there is an added interest in the fact they occurred consecutively in the routine post-mortem work of the above institution.

CASE 1.-This man, a baker, aged 66 years, was admitted to the Royal Infirmary, Glasgow, on Dec. 29th, 1908, with a history of loss of appetite and flesh for the previous 18 months, and occasional vomiting for the pelst ten months. Shortly before admission there was swelling of the abdomen and lower limbs. There was a marked alcoholic history The urine in hospital contained albumin and tube casts, $\mathrm{He}$ died quite suddenly and unexpectedly on Jan. 7th, 1909, his only complaint at the time being of moderate epigastric pain.

Neoropsy. - The pericardial sac was distended with liquid and clotted blood, the clot forming a complete sheath about half an inch thick round the heart and vessels as far as the apex of the pericardium. The clot removed weighed $8 \frac{1}{2}$ ounces, while the liquid blood measured 12 ounces. The myocardium showed marked brown atrophy. The left ventricle was moderately hypertrophied. The mitral and tricuspid valves appeared healthy and competent. The aortic and pulmonary valves were competent to the water test, but both vessels were distinctly though not greatly dilated. The wall of the aortic arch was very thin and soft, but no naked-eye degenerative changes were observable. The wall was elastic, but the finger could be pushed through it with comparative ease. Round the root of the aorta and pulmonary artery was a firm mass of blood clot. The coronary arteries were dilated and their lumina were quite free, but they showed throughout numerous soft yellowish patches projecting slightly internally. Just above the right coronary, and extending horizontally for a distance of one and a quarter inches, was a tear through its inner and middle coats. From this the blood had escaped and dissected a path for a short distance under the adventitia at this part and finally had burst through the ad. ventitia near the origin of the left coronary artery (see Fig. 1). In the thoracic and abdominal aorta,

FIG. 1.

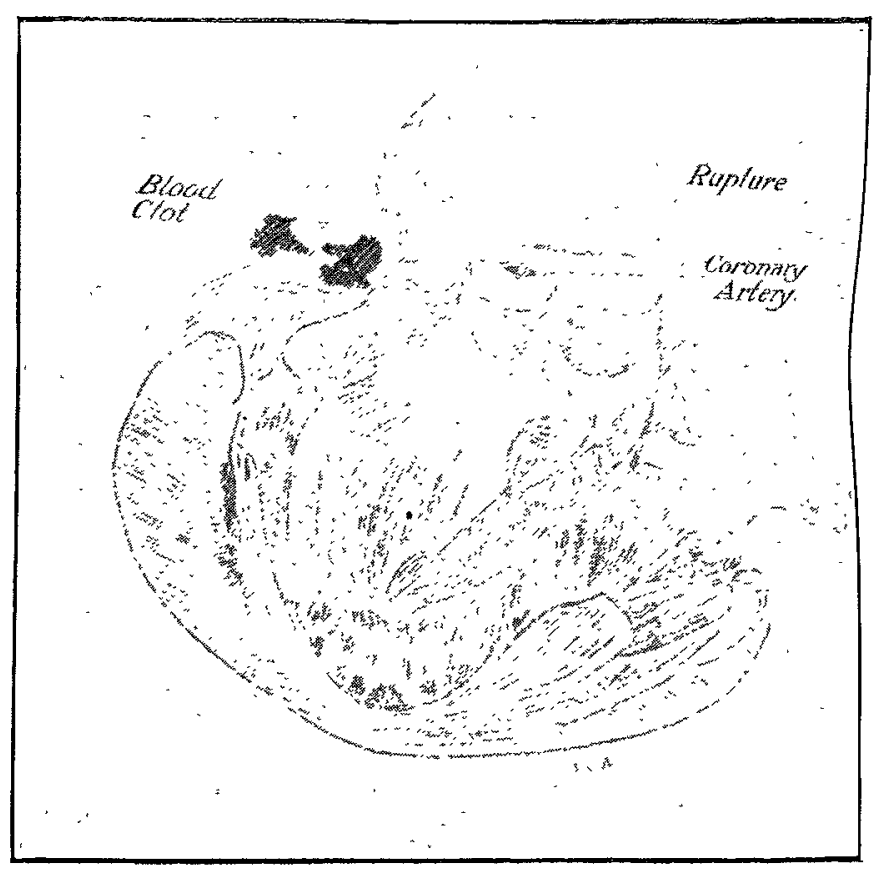

especially the latter, there was considerable soft athe romatous deposit, but no calcareous particles or atheromatous ulceration. The stomach was the seat of $a$ soft carcinoma involving almost the entire organ but leaving the csophageal and pyloric openings unaffected. The ileum showed a Meckel's diverticulum. The kidneys were granular, normal in weight, with adherent capsules and some apparent atrophy of the cortex. The other organs appeared healthy. The arteries throughout were thin-walled, but less so in degree than the aorta. Sections of the aortic wall near the site of rupture showed a remarkable paucity of elastic fibres, but neither fatty nor calcareous deposit.

CASE 2. - The patient was a storeman, aged 65 years, who died a few hours after admission on Jan. 6th last. For the past two years he had complained of pain in the epigastric region, but until Jan. 3rd, three days before admission, there had never been vomiting, and he was at work regularly, with the exception of occasional spells of alcoholic excess. There was a long history of alcoholic indulgence. From Jan. 3rd there had been occasional attacks of vomiting, the vomit on each occasion containing small quantities of fresh blood. He was at work as usual on Jan. 6th, when about mid.day he collapsed and complained of severe epigastric pain. This 
vomiting continued almost without interruption until his death a few hours afterwards.

Necropsy.-The body was remarkably well developed. There was considerable excess of subcutaneous fat generally. The pericardium was healthy and there were no adhesions, but there was an area of recent ecchymosis over the middle part of the left coronary artery. Externally the myocardium appeared healthy, with the exception of a softened area round and including the area of ecchymosis described. All the valves of the heart appeared healthy and competent. There was a flattened recent but adherent thrombus in the right auricular appendage. There was much fatty deposit over the ventricles. The aorta was much dilated throughout and showed advanced patchy atheromatous degeneration at all parts with considerable calcareous deposit. Dissection of the left coronary artery showed its orifice quite free, but about half an inch distal to this, and after the origin of two branches, the vessel was completely blocked by a thrombus which extended from this point for nearly half an inch. The thrombus seemed to have originated from a hard calcareous patch at this portion of the vessel. Beyond the thrombus the artery was unobstructed, but here again it showed advanced calcareous change. The right coronary artery was free, but its lumen was distinctly narrowed from similar calcareous deposit. In the lower half of the interventricular septum there was extensive necrosis of the myocardium, in the centre of which was a large, irregular, gaping orifice which led directly into the right ventricular cavity, the opening being much larger on the left ventricular aspect. (See Fig. 2.) Almost the entire

FIG. '2.

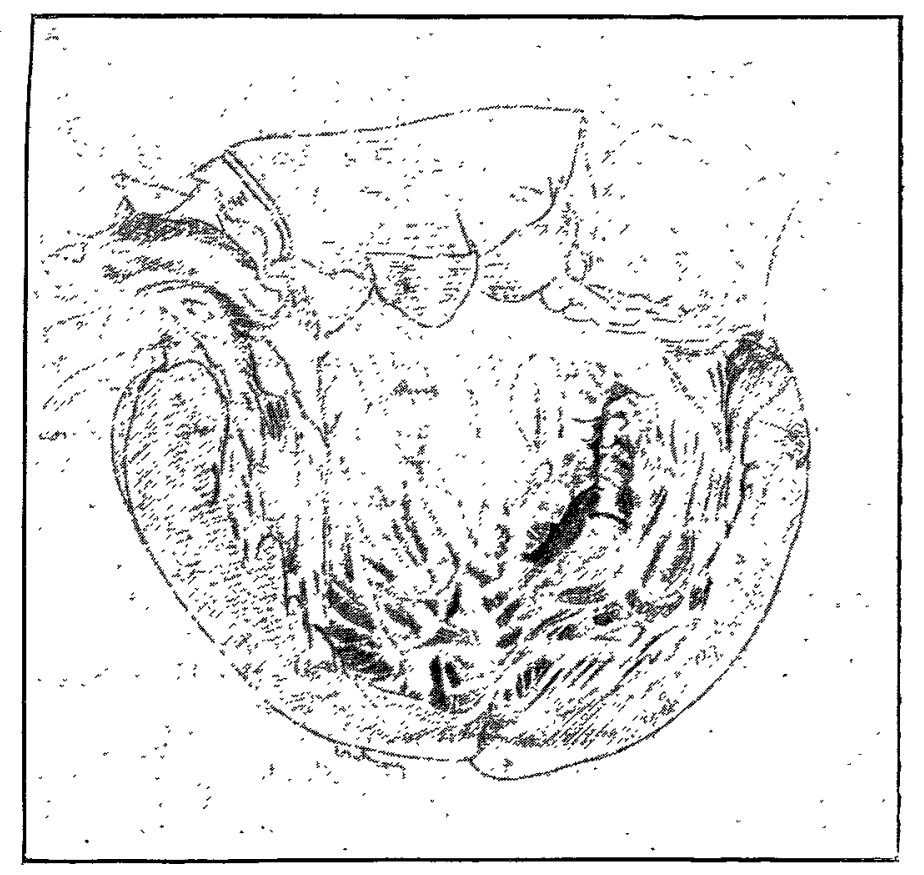

lower half of the septum was of a yellowish-white colour from anæmic necrosis; to the touch this part was very soft, and it broke down on slight pressure. At all other parts the myocardium appeared quite healthy. The stomach showed a recent shallow ulcer involving the mucous membrane only. Apart from this the other organs of the body appeared healthy.

These cases are rare enough to be worth putting on record; while the only symptom complained of in both-viz., epigastric pain-is also worthy of note.

The photographs illustrating the cases here reproduced were taken by myself from sketches made from the organs shortly after the necropsies by my assistant, Dr. A. M. Kennedy.

Glasgow.

Invalid Children's Aid Association.-The annual meeting of this association will be held by kind permission of Lord and Lady Newlands at 16, Grosvenorplace, S.W., on Tuesday, May 25th, at 3 P.M. FieldMarshal Lord Grenfell will preside. Tickets of admission can be obtained on application to the secretary at 69 , Denison House, Vauxhall Bridge-road, S.W.

\section{BILHARZIA HAMATOBIA AND CIRCUM- CISION.}

BY JAMES F. ALLEN, M.D., M.CH. R.U.I.

CONSULTING MEDICAL OFFICER TO THE NATAL GOVERNMENT RAIIWAYS.

THE generally received view of the method of entrance into the body of the bilharzia is that it gains an entrance into the stomach through the water taken for drinking. But a careful observation of the condition of bilharziosis extending over many years has led me to be more convinced as I proceeded that in every instance the parasite gains access to the body while those affected are bathing, and in the great majority of instances, in Natal anyway, that invasion took place through the urethra alone. It is possible, and I think sometimes happens, that it also enters the rectum and intestinal canal by the anus, and it may enter the lungs by infested water being sniffed into those organs while bathing, though I have never met with such a case. But wherever it is found it has got to its final resting place directly from outside and has not reached it from the vascular system. There can be no doubt but that the parasite does enter the stomach in drinking water, but it appears pretty certain the gastric juice destroys it, and that therefore it does not penetrate the tissues of that organ, reach the great veins, and so travel to its final destination. It is difficult to understand how it could ever have been maintained that so great a parasite possessing such immense fecundity and so large an egg many times greater than a blood corpuscle, and with a very hard shell, could exist in the great veins and life be continued; not only life, but good healih. In my long experience in Natal $I$ have never met with a fatal case, but, on the contrary, many recoveries.

In this inquiry it is a matter of first importance to establish the mode by which the parasite does reach its destination, for once the way by which it gains an entry into the body is discovered some means may be devised of protection. Under the received view, if incorrect no advance can be made, and the gravity of that opinion being very great causes much mental uneasiness and in some instances material loss, for if it was the case the lives of those affected ought not to be assurable; but as a matter of fact under the real state of things the parasite does not affect longevity; and finally, it is always necessary to get at the truth. I propose therefore to make another attempt to establish the real mode of entry.

In those localities where the bilharzia is prevalent the invasion of the parasite is for the most part confined to those who have contracted it when children and is almost altogether found among males. Adult invasion, though occurring under certain conditions, to which I will presently refer, is comparatively rare. The children, and for the most part the adults, in whom it appears are almost invariably persons who are in the habit of bathing in infested streams. If therefore the population of a bilharzial district was divided into river bathers and non-river bathers it would be found that the great majority of river bathers had become invaded, and of those affected nearly all contracted the condition under the age of puberty and were males ; thus, evidently habit, sex, and age are predisposing causes. In their bathing habits little boys of this country are much the same as elsewhere; they go during the warm weather frequently to the river, stay long in the water, and rarely dry themselves with towels when they come out, and they do not wear bathing drawers. The influence of sex is" not as great as would appear from the preponderance of boys affected. I think boys are more susceptible, but even of that I am not sure, they certainly offer more facilities for the entry of the parasite. The real cause of the excessive number of boys affected is that they more frequently bathe in the open streams than girls and that they mostly discard the use of towels. Thus the parasites are able to cling to the parts of their bodies which facilitate invasion.

Age undoubtedly does influence invasion, the great majority of those affected being boys under the age of puberty. The bathing habits of the boys to some extent account for this; but it is mainly due to the ease with which the parasite can enter the urethra before the prepuce is retracted. There can be no doubt but that the prepuce plays a most important part in the entry of the "parasite T.? 